\title{
Flucht ist keine Lösung
}

_ Advent, die Zeit, in der man in eine Decke gekuschelt mit einer dampfenden Teetasse vor dem Kaminfeuer sitzt und das Jahr Revue passieren lässt. Ihnen kommt das nicht bekannt vor? Mir auch nicht. Und zwar nicht, weil wir keinen Kamin haben - die Kaminfeuer-DVD täte es zur Not ja auch. Nein, ich gerate ab spätestens Ende November in einen Ausnahmezustand, in dem für besinnliches Teetrinken einfach keine Zeit ist: Vanillekipferl für den Liebsten backen, den Adventskalender fürs Patenkind füllen, ein Geschenk für Opa finden, der schon alles hat. An Heiligabend sitze ich geplättet unterm Baum und nehme mir noch ein bisschen fester als im vergangenen Jahr vor, den nächsten Advent geruhsamer angehen zu lassen.

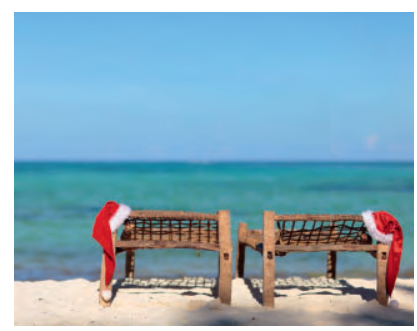

_ Letztes Jahr überlegte ich zum ersten Mal, ob ich wohl meinen Jahresurlaub einmal sammeln und den kompletten Dezember fliehen sollte. Irgendwohin, wo es keine blinkenden Weihnachtsmännermützen gibt. Doch kurz nach Silvester: Ich sitze mit einer heißen Schokolade und der Dezember-Ausgabe von „Schöner Wohnen“ auf dem Sofa. Seite 1, das Editorial. Chefredakteur Stephan Schäfer beschreibt exakt das, was ich insgeheim geplant hatte: die Flucht aus dem Weihnachtstrubel. Er flog nach Thailand. Schnorcheln statt Shoppen. Geniale Vorstellung. Am Heiligen Abend saß er in einer Bar an einem Puderzuckerstrand, bewunderte die faustgroßen Muscheln - und musste bemerken, dass sein Fluchtplan nicht aufging. Die Frage, die ihn beschäftigte, war nicht, ob er noch einmal tauchen gehen sollte, sondern ob die Gans im Ofen seiner Mutter wohl schon gar war. Als der Kellner - mit blinkender Weihnachtsmannmütze - zwei Mango Margarita brachte, schwor er sich, Weihnachten künftig zu Hause zu bleiben.

- Wunderbare Weihnachten und einen guten Rutsch ins neue Jahr!
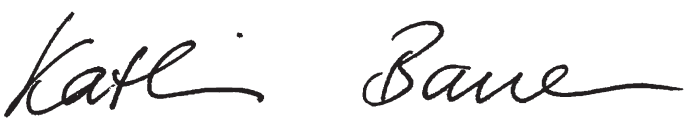

PS: Damit Ihre Adventszeit möglichst stressfrei wird, haben wir für Sie auf Seite 62 Geschenktipps aus der Redaktion gesammelt. Falls Sie Ruhe und Gelassenheit wünschen, dann blättern Sie auf Seite 34. Helko Brunkhorst stellt Rücken Qi Gong vor - Entspannung pur.
Weihnachten weit weg von zu Hause - für mich keine Lösung (mehr)

\section{ZU GEWINNEN}

In jeder physiopraxis werden attraktive Gewinne verlost. Möchten Sie einen ergattern, klicken Sie unter www.thieme.de/physioonline auf „physiopraxis-exklusiv“.

Und das gibt es in dieser Ausgabe zu gewinnen:

Bücher

2-mal „Gesprächsführung für Physiotherapeuten“

Seite 30

2-mal „Stress- und Schmerzursachen verstehen“ Seite 30

5-mal „Rücken Qi Gong“ Seite 35

5-mal „Therapeutenhandbuch Botulinumtoxin und Spastik" Seite 38

und außerdem

3-mal je 4 Poster mit allen Rücken-Qi-Gong-Übungen Seite 35

2 iPad-Apps

„3D Muscle Premium 2“ Seite 45

3 Antistressbälle

Seite 71

1 mobile Therapieliege

Seite 95

1 Liegenbezüge-Set

Seite 95

1 Duschtücher-Set

Seite 95

1 Übertöpfe-Set 